\title{
Evaluation of Radicular Dentin Microcracks Formation after Instrumentation with NiTi Hand and Rotary File System: A Stereomicroscopic Study
}

\author{
Ajay Kumar ${ }^{1}$, Shalan Kaul ${ }^{2}$, Feby Kuriakose ${ }^{3}$, Jittin James ${ }^{4}$, Basil Joy ${ }^{5}$, Reema Malik ${ }^{6}$
}

\begin{abstract}
Aim and objective: The present study aimed to assess the formation of microcracks in root dentin post-instrumentation with nickel-titanium (NiTi) hand and rotary file system.

Materials and methods: Totally, 80 freshly extracted mandibular premolar teeth with single roots were chosen for this study. Access opening was performed and \#10 K-file was used to attain patency of canal. All specimens were divided into four groups (each group having 20 specimens), i.e., Group I: Unprepared, Group II: NiTi hand K-files, Group III: Self-adjusting file, and Group IV: XP-Shaper single file. Complete irrigation of all the canals was performed after instrumentation. All roots were cut horizontally at three levels [apical third ( $3 \mathrm{~mm})$, middle third (6 mm), and cervical third $(9 \mathrm{~mm})]$ from the apex with diamond disc. A stereomicroscope was used to view the sections under $20 \times$ magnification.

Results: Self-adjusting file showed least number of defects with a percentage of $75 \%$ followed by XP-Shaper and NiTi hand K-files with a values of 65 and $60 \%$, respectively. Use of hand K-files resulted in greater number of incomplete cracks (30\%) and use of XP-Shaper demonstrated greater number of craze lines (15\%). A statistically significant difference was found between the experimental groups in the formation of dentinal defects of root at apical third $(3 \mathrm{~mm})(p<0.031)$ and middle third $(6 \mathrm{~mm})(p<0.001)$, whereas the sections at cervical third $(9 \mathrm{~mm})$ did not show any statistically significant difference $(p>0.312)$.

Conclusion: The present study concluded that the self-adjusting file system gives promising better results in cleaning ability with minimal incidence of radicular dentin microcracks than XP-Shaper and NiTi hand K-files system.

Clinical significance: The root dentin may unavoidably get damaged during instrumentation resulting in the formation of dentinal cracks and tiny complicated fractures, thus leading to endodontic failures. Various factors cause dentinal cracks, but the flexibility of file due to heat treatment, kinematics of the file, and the basic architecture of the file are the most significant ones. Self-adjusting file system represented satisfactory results with minimal microcracks defects.

Keywords: Dentin microcracks, Hand files, Nickel-titanium files, Stereomicroscope.

The Journal of Contemporary Dental Practice (2020): 10.5005/jp-journals-10024-2955
\end{abstract}

\section{INTRODUCTION}

One of the significant steps in endodontic therapy is root canal preparation. This involves elimination of necrotic and vital tissues and infected dentin from the root canals. The objective of such a root canal preparation is to aid use of disinfecting medicaments and irrigants, subsequently eradicating infection, and avoiding repeated infections accomplished through providing a fluid tight endodontic filling and restoration of tooth crown. The mechanical and biological objectives of endodontic therapy depend on thorough irrigating and shaping of the root canals. ${ }^{1}$

Over the past several years, preparation of root canals was being performed efficaciously with the use of hand instruments. Advanced automated systems involving various mechanics have led to the use of nickel-titanium instruments resulting in an alternate enhanced technique, thus enhancing the ability to shape and to reduce the incidence of fracture of instrument during endodontic therapy. ${ }^{2}$

Since the last 10 years, full-fledged popularity of nickel-titanium (NiTi) rotary instruments use has been growing and different registered systems have been familiarized commercially. The most important benefits of NiTi files are reduced working time and enhanced flexibility. ${ }^{3}$

Sometimes the root dentin may get damaged unavoidably during instrumentation resulting in endodontic treatment failure
${ }^{1}$ Department of Conservative Dentistry and Endodontics, Indira Gandhi Government Dental College and Hospital, Jammu, India

${ }^{2}$ Department of Pedodontics and Preventive Dentistry, Indira Gandhi Government Dental College and Hospital, Jammu, India

${ }^{3,5}$ Department of Conservative Dentistry and Endodontics, Mar Baselios Dental College, Kothamangalam, Kerala, India

${ }^{4}$ Department of Prosthodontics, Indira Gandhi Institute of Dental Sciences, Kothamangalam, Kerala, India

${ }^{6}$ Department of Conservative Dentistry and Endodontics, Maulana Azad Institute of Dental Sciences, New Delhi, India

Corresponding Author: Shalan Kaul, Department of Pedodontics and Preventive Dentistry, Indira Gandhi Government Dental College and Hospital, Jammu, India, Phone: +91 9419187672, e-mail: drshalankaul123@gmail.com

How to cite this article: Kumar A, Kaul S, Kuriakose F, et al. Evaluation of Radicular Dentin Microcracks Formation after Instrumentation with NiTi Hand and Rotary File System: A Stereomicroscopic Study. J Contemp Dent Pract 2020;21(11):1233-1237.

Source of support: Nil

Conflict of interest: None

due to the formation of tiny but complex fractures and dentinal cracks. ${ }^{4}$ Dentinal microcracks pose difficulty to instrumentation and restorative procedures which further decreases tooth resistance

(0) Jaypee Brothers Medical Publishers. 2020 Open Access This article is distributed under the terms of the Creative Commons Attribution 4.0 International License (https://creativecommons.org/licenses/by-nc/4.0/), which permits unrestricted use, distribution, and non-commercial reproduction in any medium, provided you give appropriate credit to the original author(s) and the source, provide a link to the Creative Commons license, and indicate if changes were made. The Creative Commons Public Domain Dedication waiver (http://creativecommons.org/publicdomain/zero/1.0/) applies to the data made available in this article, unless otherwise stated. 
and leads to vertical root fracture (VRF). The most complicated feature of endodontic therapy failure is VRF, which ultimately leads to extraction of tooth. Frequent and recurrent occlusal forces lead to propagation of microcrack and subsequent root fracture. ${ }^{5}$ Therefore, the present study was conducted to assess the formation of microcracks in root dentin post-instrumentation with NiTi hand and rotary file system.

\section{Materials and Methods}

The present study was conducted in the department of conservative dentistry and endodontics, Indira Gandhi Government Dental College, Jammu, India. Totally, 80 freshly extracted mandibular premolar teeth with single roots were chosen for this study. The teeth were extracted for various orthodontic reasons. Calculus, soft tissue, and debris were cleaned off the extracted teeth with the use of an ultrasonic scaler and were kept in saline until further use. A stereomicroscope was used to observe all the roots under a magnification of $\times 10$ to identify any fracture or crack that was previously present, and such specimens were excluded from the study. Presence of single canal was identified using radiographs.

A diamond coated bur was used to flatten each specimen's coronal portion under running water for cooling. The access cavity was opened; canal patency was established with \#10 K-file (MicroMega, Besancon, France) in each root. A working length short of $0.5 \mathrm{~mm}$ of the file seen at the apical foramen was established. About $3 \mathrm{~mL}$ of sodium hypochlorite $(\mathrm{NaOCl})$ solution of $2.5 \%$ concentration by a $30-G$ needle was used for irrigation.

\section{Preparation for Root Canal}

All enrolled specimens were divided into four groups (each group having 20 specimens).

\section{Group I: Unprepared}

Twenty unprepared specimens were taken as controls.

\section{Group II: NiTi Hand K-files}

The root canals were enlarged using $25 \mathrm{~K}$ size NiTi hand $\mathrm{K}$-files adapting the technique of balanced force. A one-fourth-turn of $90^{\circ}$ clockwise rotation was followed to insert the files with no apical pressure and counter-clockwise rotation of $120^{\circ}$ was applied with sufficient apical pressure for cutting.

\section{Group III: Self-adjusting file}

Instrumentation with hand-held K-files till apical size was reached followed by use of self-adjusting file $(1.5 \mathrm{~mm}$ ) (ReDent Nova, Israel) with 5000 vibrations per minute and an amplitude of $0.4 \mathrm{~mm}$ for instrumentation.

\section{Group IV: XP-Shaper Single file}

Hand-held K-files were used till apical size for instrumentation followed by use of XP-Shaper file (FKG Dentaire, Swiss) in constant motion of rotation at an $800 \mathrm{rpm}$ consistent speed and $1 \mathrm{~N} / \mathrm{cm}$ torque was used for instrumentation. An in and out motion of the files was used to facilitate their movement gradually down the canals. An upward filing motion was used circumferentially without any pressure to reduce and overcome cervical interferences.

A $3 \mathrm{~mL}$ solution of $2.5 \% \mathrm{NaOCl}$ was used to irrigate all the canals post the use of individual file. Finally, a $1 \mathrm{~mL}$ solution of $17 \%$ EDTA was used to rinse all the canals, which was later followed again by a $\mathrm{NaOCl}$ rinse.

\section{Preparation for Sectioning and Microscopic Analysis}

All roots were cut horizontally at three levels [apical third ( $3 \mathrm{~mm})$, middle third $(6 \mathrm{~mm})$, and cervical third $(9 \mathrm{~mm})]$ from the apex with diamond disc under constant water cooling. Each specimen was examined by a single investigator. A stereomicroscope (Olympus, Tokyo, Japan) was used to view the sections under $20 \times$ magnification. The cracks appeared were recorded using digital pictures (Fig. 1).

\section{Assessments of Radicular Defects were Classified as Follows According to Barreto et al. ${ }^{6}$}

- No defect: Absence of any cracks or lines on the internal or external surface of the root dentin.

- Incomplete crack: A line progressing into the dentin from the canal wall and not reaching the outer surface.

- Complete crack: A line progressing to the root's outer surface from the wall of root canals.

- Craze lines: All the remaining lines that did not spread to any root surface or progressed into the dentin from the outer surface none the less reached the wall of root canals.

\section{Statistical Analysis}

The number and percentage of dentinal defects in root were analyzed in all the groups. The Statistical Package for Social Sciences (SPSS) version 20.0 was used to perform statistical tests. The chisquare test was used to statistically analyze each group. A $p$ value of $<0.05$ was considered statistically significant.

\section{Results}

Table 1 shows the overall radicular dentin microcracks in all the groups, in which self-adjusting file showed least number of defects with a percentage of $75 \%$ followed by XP-Shaper and NiTi hand K-files with a values of 65 and $60 \%$, respectively. Use of hand K-files resulted in greater number of incomplete cracks (30\%) and use of XP-Shaper demonstrated greater number of craze lines (15\%).

When each system of file was compared for the results achieved at sections of apical third ( $3 \mathrm{~mm})$, middle third $(6 \mathrm{~mm})$, and cervical third $(9 \mathrm{~mm})$, statistically significant difference was found between the experimental groups in the formation of dentinal defects of root at apical third $(3 \mathrm{~mm})(p<0.031)$ and middle third $(6 \mathrm{~mm})$ $(p<0.001)$, whereas the sections at cervical third $(9 \mathrm{~mm})$ did not show any statistically significant difference $(p>0.312)$, as shown in Tables 2 to 4.

The inference of the present study indicates that the selfadjusting file systems have potential favorable results in their ability to clean the canals thoroughly and induce least root dentin microcrack occurrences in comparison with NiTi hand K-files and XP-Shaper files system.

\section{Discussion}

The utmost significant step in endodontic therapy is preparation of root canals. The idea of "Cleaning and shaping of the root canals" was familiarized by Schilder around 30 years ago and the objective of this is canal space preparation to enable disinfection by irrigating solutions and use of other medicaments and further facilitate root 

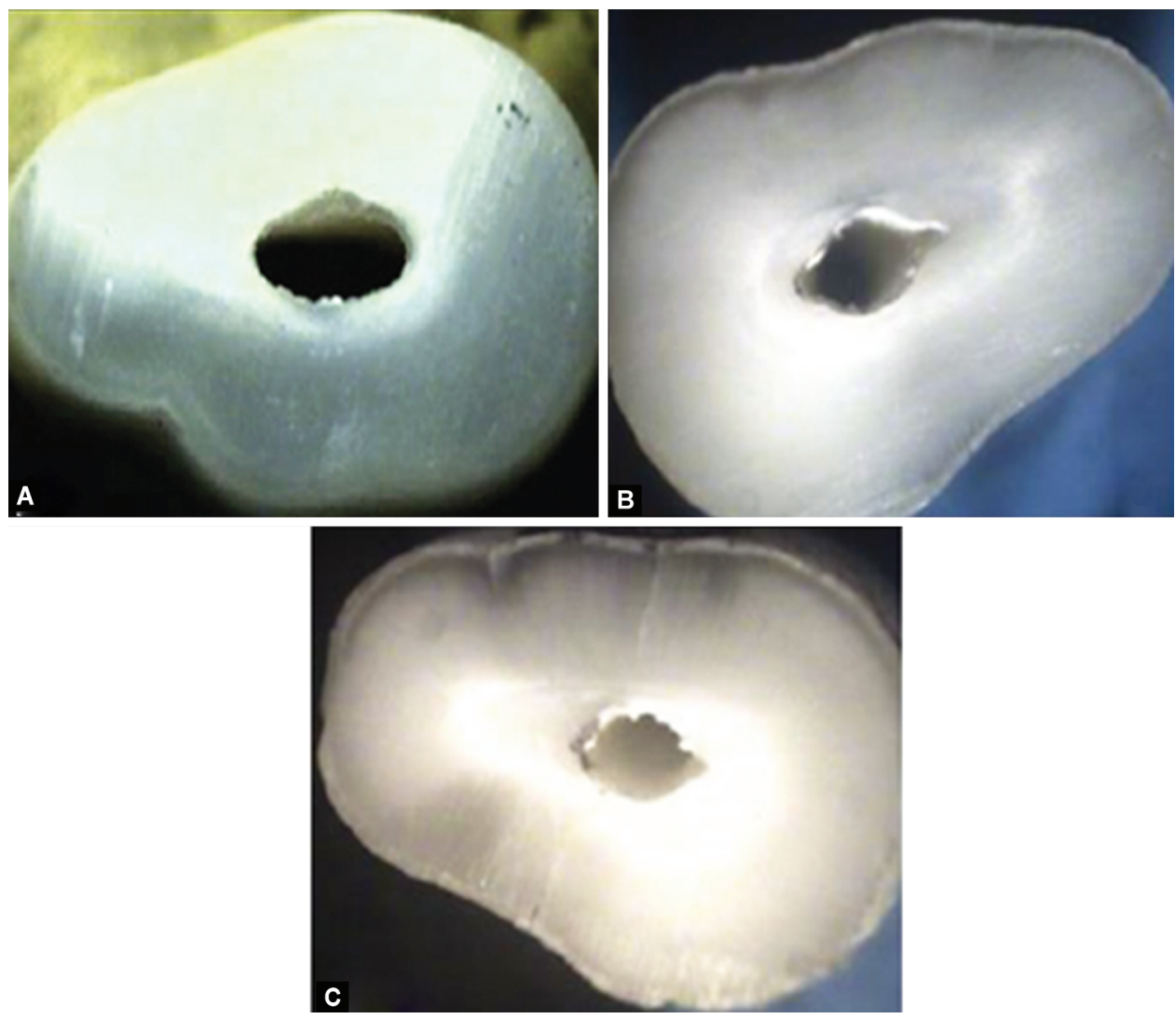

Figs 1 A to C: Stereomicroscopic images of (A) NiTi hand K-file; (B) Self-adjusting file; (C) XP-Shaper file

Table 1: Overall radicular dentin microcracks in all the groups

\begin{tabular}{llllll}
\hline Groups & Total samples $n$ & No defect $n(\%)$ & Incomplete crack $n$ (\%) & Complete crack $n$ (\%) & Craze lines $n$ (\%) \\
\hline Group I: Unprepared & 20 & $20(100)$ & 0 & 0 & 0 \\
Group II: NiTi hand K-files & 20 & $12(60)$ & $6(30)$ & 0 & $2(10)$ \\
Group III: Self-adjusting file & 20 & $15(75)$ & $3(15)$ & 0 & $2(10)$ \\
Group IV: XP-Shaper & 20 & $13(65)$ & $4(20)$ & 0 & $3(15)$ \\
\hline
\end{tabular}

Table 2: Percentage comparison of radicular dentin microcracks at apical third ( $3 \mathrm{~mm}$ )

\begin{tabular}{|c|c|c|c|c|c|c|}
\hline Groups & No defect $n(\%)$ & Incomplete crack n (\%) & Complete crack $n(\%)$ & Craze lines $n(\%)$ & Chi-square value & $p$ value \\
\hline Group I: Unprepared & $20(100)$ & 0 & 0 & 0 & 12.168 & 0.031 \\
\hline Group II: NiTi hand K-files & $19(95)$ & 0 & 0 & 0 & & \\
\hline Group III: Self-adjusting file & $18(90)$ & $1(5)$ & 0 & $1(5)$ & & \\
\hline Group IV: XP-Shaper & $18(90)$ & $1(5)$ & 0 & $1(5)$ & & \\
\hline
\end{tabular}

Table 3: Percentage comparison of radicular dentin microcracks at middle third (6 mm)

\begin{tabular}{|c|c|c|c|c|c|c|}
\hline Groups & No defect $n(\%)$ & Incomplete crack n (\%) & Complete crack $n(\%)$ & Craze lines $n(\%)$ & Chi-square value & $p$ value \\
\hline Group I: Unprepared & $20(100)$ & 0 & 0 & 0 & 10.868 & 0.001 \\
\hline Group II: NiTi hand K-files & $15(75)$ & $4(20)$ & 0 & 1 & & \\
\hline Group III: Self-adjusting file & $18(90)$ & $1(5)$ & 0 & $1(5)$ & & \\
\hline Group IV: XP-Shaper & $17(85)$ & $2(10)$ & 0 & $1(5)$ & & \\
\hline
\end{tabular}

Table 4: Percentage comparison of radicular dentin microcracks at cervical third (9 mm)

\begin{tabular}{|c|c|c|c|c|c|c|}
\hline Groups & No defect $n$ (\%) & Incomplete crack n (\%) & Complete crack $n(\%)$ & Craze lines $n(\%)$ & Chi-square value & $p$ value \\
\hline Group I: Unprepared & $20(100)$ & 0 & 0 & 0 & 9.012 & 0.312 \\
\hline Group II: NiTi hand K-files & $18(90)$ & $2(10)$ & 0 & $1(5)$ & & \\
\hline Group III: Self-adjusting file & $19(95)$ & $1(5)$ & 0 & 0 & & \\
\hline Group IV: XP-Shaper & $18(90)$ & $1(5)$ & 0 & $1(5)$ & & \\
\hline
\end{tabular}


canal space obturation three-dimensionally. Therefore, root canal preparation is the most important step of endodontic therapy that eradicates infection.

During the process of root canal preparation, momentary stress absorption gets developed along the contact between the walls of the canal and instrument in root dentin, which may result in dentinal defects, thus initiating VRF. The formation of microcracks may be linked to features of instrument, such as taper, design of tip, pitch design, cross-sectional geometry, and flute form. ${ }^{8}$

In the present study, a microscope was used to observe all roots under a magnification of $\times 10$ to identify the occurrence of any fracture or crack which previously existed. This is in accordance with the trial by Langaliya et al. ${ }^{9}$ who examined the presence of preexisting fracture or cracks in all teeth. Yet, identifying the cracks prior to the initiation of the experiment is problematic as few of these cracks may be present internally and may not be seen on the exterior. However, the control group did not show any cracks, suggesting that the microcracks seen were due to procedures of preparation with NiTi files.

In the present study, improved results in terms of cleaning ability and least occurrence of microcracks in root dentin were demonstrated by self-adjusting file system than XP-Shaper and NiTi hand K-files system. This result in contradictory to the in vitro trials by Bier et al. ${ }^{10}$ and Ashwinkumar et al. ${ }^{11}$ found minimal incidence of microcracks in teeth that were instrumented using hand file than in those using mechanical instrumentation. In the past decade, several novel NiTi rotary and reciprocating arrangements have been established and presented in the market. A possible relationship could exist between frequency of microcrack formation and $\mathrm{NiTi}$ instruments' design, because it has been shown the design of file may impact concentration of strain and stress in apical region during instrumentation of root canals. ${ }^{12}$

A trial by Mohammed et al. ${ }^{13}$ showed least dentinal defects incidence in radicular dentin after use of XP-Shaper for instrumentation and it was found that XP-Shaper is prefabricated with the Ni-Ti MaxWire. Due to metallurgical alloy, the instrument has super elasticity, high flexibility, and increased fatigue resistance. The formation of microcracks in dentin may be prevented due to the enhanced flexibility of these files. ${ }^{14}$

The use of self-adjusting files to instrument the tooth specimens showed least cracks in the present study. This is due to nonapplication of rotational movement and application of constant delicate pressure on the walls of radicular dentin by these files and this permits an even dentin removal along the entire root canal perimeter. The application of vibrating movement in an in and out direction in place of complete rotation results in reduced concentration of stress in the root canal. Additionally, the non-stop irrigation with the use of self-adjusting file led to reduced friction and enabled the easy dentin removal. These findings are similar to those obtained by Yoldas et al., ${ }^{8}$ Hof et al., ${ }^{15}$ Peters and Paque ${ }^{16}$ who demonstrated lack of dentinal cracks in root canals instrumented with self-adjusting file system.

The technique used to store the samples is important too as a desiccated tooth will have diminished resistance to the applied forces in each path throughout the process of instrumentation and filling or the examination through scanning or cutting the samples. It has been testified that in a tooth root which is not dehydrated, radicular dentin microdefect formation or increase in remaining microstrain does not take place. ${ }^{17}$ Yet, another factor which may impact the outcome of such trials is the tooth's age. In about $30 \%$ of older teeth, a decrease in crack propagation and an increase in resistance to fracture have been reported because of the reduced area of lumen and mineral deposition. ${ }^{18}$ The results of Bajaj et al. ${ }^{19}$ have reported a reduction of crack growth and an increase in fracture resistance of about $30 \%$ for older teeth due to the reduction of the lumen area and deposition of mineralized structure.

A diverse suggested torque and speed was used for the files system in the present study which cannot be regularized for all other files. The limitation of this study could be the use of varying torque and speed situation for each file system. Similarly, it was not easy to regularize the force used in downward motion during instrumentation. Moreover, teeth chosen for this study were those with no anatomic complications and with straight root canals which actually failed to duplicate real clinical scenario.

\section{Conclusion}

The present study concluded that the, self-adjusting file system gives promising better results in cleaning ability with minimal incidence of radicular dentin microcracks than XP-Shaper and NiTi hand K-files system.

\section{References}

1. Song YL, Bian Z, Fan B, et al. A comparison of instrument-centering ability within the root canal for three contemporary instrumentation techniques. Int Endod J 2004;37(4):265-271. DOI: 10.1111/j.01432885.2004.00798.x.

2. Thompson SA. An overview of nickel-titanium alloys used in dentistry. Int Endod J 2000;33(4):297-310. DOI: 10.1046/j.13652591.2000.00339.x.

3. Pujari H. Stress distribution of new generation of twisted files in comparison with ProTaper: a finite element analysis. Saudi Endod J 2013;3(2):65-69. DOI: 10.4103/1658-5984.118149.

4. Peters OA. Current challenges and concepts in the preparation of root canal systems: a review. J Endod 2004;30(8):559-567. DOI: 10.1097/01. DON.0000129039.59003.9D.

5. Yoshino K, Ito K, Kuroda M, et al. Prevalence of vertical root fracture as the reason for tooth extraction in dental clinics. Clin Oral Investig 2015;19(6):1405-1409. DOI: 10.1007/s00784-014-1357-4.

6. Barreto MS, MoraesRdo A, Rosa RA, et al. Vertical root fractures and dentin defects: effects of root canal preparation, filling and mechanical cycling. J Endod 2012;38(8):1135-1139. DOI: 10.1016/j. joen.2012.05.002.

7. Amitha M, Adarsha MS, Meena N, et al. Comparative assessment of formation of dentin microcracks after root canal preparation using hand, rotary, and reciprocating instrumentation - an in vitro study. Int J Oral Care Res 2018;6(2):S19-S23.

8. Yoldas O, Yilmaz S, Atakan G, et al. Dentinal microcrack formation during root canal preparations by different NiTi rotary instruments and the self-adjusting file. J Endod 2012;38(2):232-235. DOI: 10.1016/j. joen.2011.10.011.

9. Langaliya AK, Kothari AK, Surti NR, et al. In vitro comparative evaluation of dentinal microcracks formation during root canal preparation by different nickel-titanium file systems. Saudi Endod J 2018;8:183-188.

10. Bier CAS, Shemesh $\mathrm{H}$, Tanomaru-Filho $M$, et al. The ability of different nickel-titanium rotary instruments to induce dentinal damage during canal preparation. J Endod 2009;35(2):236-238. DOI: 10.1016/j. joen.2008.10.021.

11. Ashwinkumar V, Krithikadatta J, Surendran S, et al. Effect of reciprocating file motion on microcrack formation in root canals: an SEM study. Int Endod J 2014;47(7):622-627. DOI: 10.1111/ iej.12197. 
12. Kubo M, Miura J, Sakata T, et al. Structural modifications of dentinal microcracks with human aging. Microscopy (Oxf) 2013;62(6):555-561.

13. Mohammed MN, Kamel WH, Rokaya ME. Comparison of the cleaning effectiveness and incidence of dentinal defects after biomechanical preparation using different ni ti rotary instruments in root canals. ADJ 2020;7(2):165-170.

14. Versiani M, Souza E, De-Deus G. Critical appraisal of studies on dentinal radicular microcracks in endodontics: methodological issues, contemporary concepts, and future perspectives. Endod Topics 2015;33(1):87-156. DOI: 10.1111/etp.12091.

15. Hof R, Perevalov V, Eltanani $M$, et al. The self-adjusting file (SAF). part 2: mechanical analysis. J Endod 2010;36(4):691-696. DOI: 10.1016/j. joen.2009.12.028.
16. Peters $O A$, Paque $F$. Root canal preparation of maxillary molars with self-adjusting file: a micro-computed tomography study. J Endod 2011;37(1):53-57. DOI: 10.1016/j.joen.2010.08.047.

17. Carlesi T, Nigro G, Di Giacomo L, et al. Dentinal microcrack formation during root canal treatment with Mtwo instruments and MicroSeal filling technique. J Adv Oral Res 2018;9(1-2):31-37. DOI: $10.1177 / 2320206818801260$.

18. Nazari A, Bajaj D, Zhang D, et al. Aging and the reduction in fracture toughness of human dentin. J Mech Behav Biomed Mater 2009;2(5):550-559.

19. Bajaj D, Sundaram N, Nazari A, et al. Age, dehydration and fatigue crack growth in dentin. Biomaterials 2006;27(11):2507-2517. DOI: 10.1016/j.biomaterials.2005.11.035. 